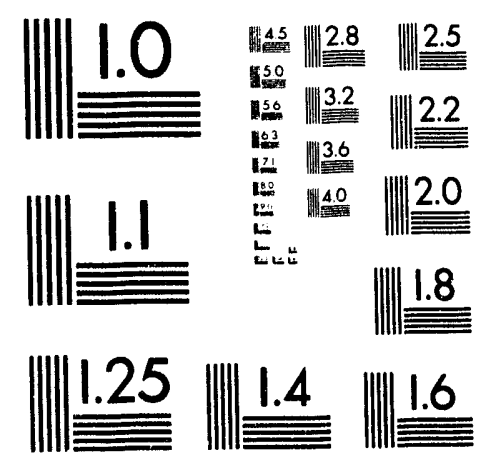



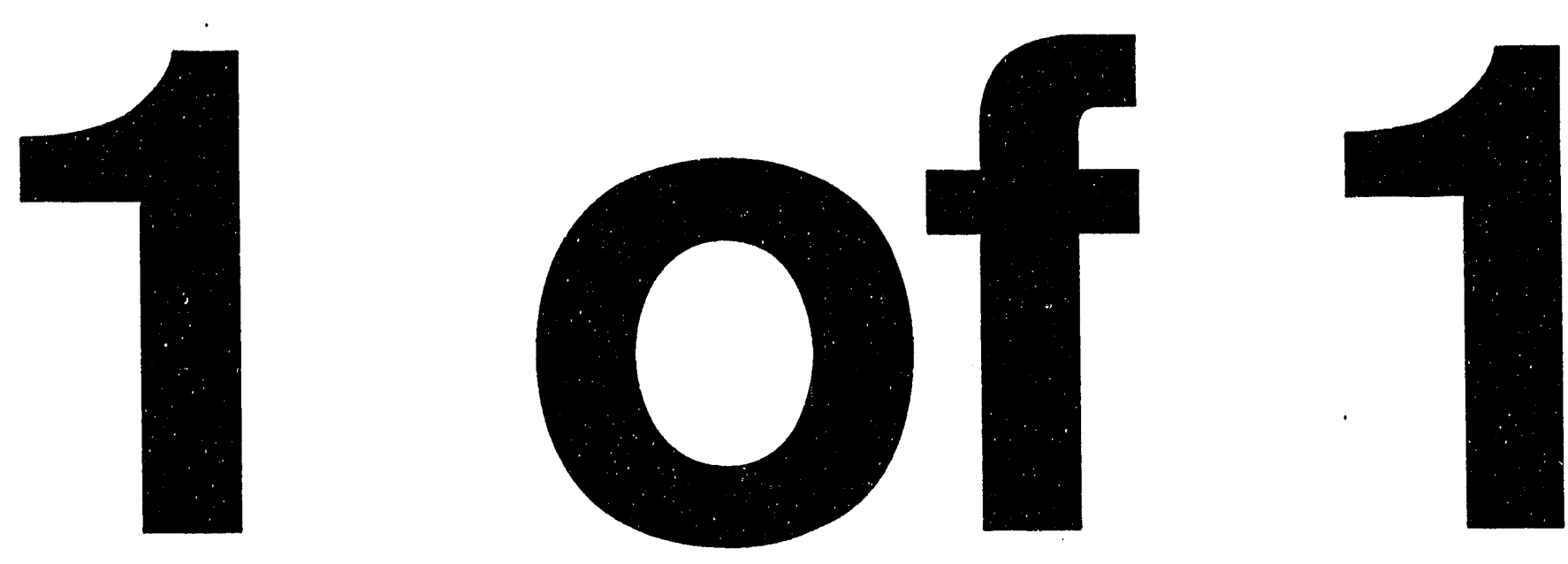
TITLE: NEW LANL GAS-DRIVEN TWO-STAGE GUN

AUthoR(S): A.R. Martinez, S.A. Sheffield, M.C. Whitehead, J.J. Dick, H.D. Olivas, LANL $/ M-7$

SUBmitted TO: Joint AIRAPT/APS Conference - American Physical Society June 28 - July 2, 1993 / Colorado Springs, CO

\section{DISCLAIMER}

This report was prepared as an account of work 8 . onsored by an agency of the United States Government. Neither the United States Government nor any agency thereof, nor any of their employees, makes any warranty, express or implied, or assumes any legal liability or responsibility for the accuracy, completeness, or usefulness of any information, apparatus, product, or process disclosed, or represents that its use would not infringe privately owned rights. Reference herein to any specific commercial product, process, or service by trade name, trademark, manufacturer, or otherwise does not necessarily constitute or imply its endorsement, recommendation, or favoring by the United States Government or any agency thereof. The views and opinions of authors expressed herein do not necessarily state or reflect those of the United States Government or any agency thereof.

By acceptance of this article. the publisher recognizes that the U.S Government retains a nonexclusive. royafly-free ficense to publish or ieproduce the published form of inis contribution. or to allow others to do so. lor U.S. Government purposes.

The Los Alamos Nationat Laboratory requests inat the publisher identily this article as work pertorted under the uuspices of the U.S Depariment of Energy.

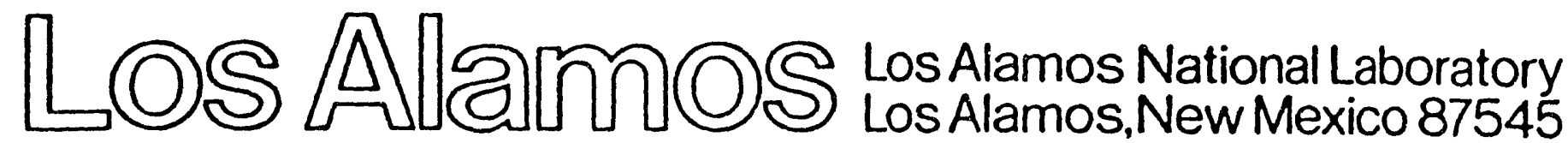




\title{
NEW LANL GAS DRIVEN TWO-STAGE GUN*
}

\author{
A. R. Martinez, S. A. Sheffield, M. C. Whitehead, H. D. Olivas, and J. J. Dick \\ Los Alamos National Laboratory \\ Group M-7, MS P952 \\ Los Alamos, NM 87545
}

A new compressed-helium driven two-stage light gas gun has been installed at LANL to study shock initiated reaction in insensitive high explosives. The gun (based on a design at Emst Mach Institute) has a 100 $\mathrm{mm}$ diameter ky 7.6 long pump tube and a $50-\mathrm{mm}$ diameter by $7.6-\mathrm{m}$ long launch tube. The gas breech, capable of pressures up to $15,000 \mathrm{psi}$, has a volume of 42.5 liters and can be used in either a wrap-around or double-diaphragm mode. This breech was designed so we could use helium rather than powder combustion gases to drive the pump piston, eliminating the safety and cleanup problems associated with gun powder. Large hydraulic clamps (pressurized to $10,000 \mathrm{psi}$ ) are used to clamp the breech to the pump tube, the pump tube to the transition section, and the transition section to the launch tube. The target chamber was designed to allow the necessary room to do multiple magnetic gauging experiments. Gun control is accomplished using a MAC computer and LabVIEW control software.

\section{INTRODUCTION}

A new two-stage (TS) gas gun has been installed at the high explosive gun facility located at DF-Site at the Los Alamos National Laboratory. The primary purpose for this new gun is to perform research and characterization studies relating to the initiation and detonation of insensitive high explosive (IHE) materials. Our single-stage (SS) gas gun is not capable of producing the projectile velocities required to initiate IHE's (such as 1,3 , 5-triamino-2, 4, 6-trinitrobenzene--TATB) or homogeneous liquid explosives (such as nitromethane). Several years ago a program was undertaken to design and install a TS gun capable of providing the higher projectile velocities required. After visits to many gun facilities, we decided to use the gun design developed by Alois Stilp at the Emst Mach Institut (EMI) in Freiburg. Germany. 1.2

The Stilp design employs two large hycraulic clamps to clamp the transition section to both the pump tube and launch tube during a shot. Large interlocking "bayonet" arrangements on each end of the transition section (extemal) and inside the hydraulic clamp (internal) allow for interlocking the two pieces before the clamps are pressurized to about 10,000 psi when preparing to shoot. This design was used as the baseline for our new gun but a number of design changes were made to render it better suited to our needs.

\footnotetext{
- Work performed under the auspices of the U.S. Department of Energy.
}

\section{GUN CALCULATIONS AND DESIGN}

Several uninue features were designed into our gun including: a gas breech (to eliminate the problems of using gun powder) capable of either wrap-around or double-diaphragm operation, a hydraulic clamp joint at the breech/pump tube interface, and a large launch tube bore (to maximize the experimental area available for 1-D experiments) so that multiple magnetic gauging experiments can be done. To determine whether or not these and other design changes would lead to a workable gun and also to help determine the final gun dimensions, a number of computer calculations to simulate gun performance were done using the gas gun code of Charters and Sangster. ${ }^{3}$ The Stilp design was used as the baseline and changes were made to the various parameters to assess expected gun performance.

Initially, calculations were made for the original Stilp design with the powder breech. Then a helium filled gas breech was substituted for the powder breech to allow a comparison. In addition, only helium was used for the pump tube gas (eliminating the problems associated with using hydrogen in the new gun). A maximum pressure of 15,000 psi was chosen for the breech because we already have a breech and the supporting pressurization equipment with this capability on our single-stage gun. It became immediately apparent that some drop in maximum projectile velocity would result from this change 
but since high velocilies were not of prime importance to us, this was deemed acceptable. Calculations were done to determine an optimum breech volume by varying the volume while holding all other parameters constant. These calculations indicated that above a volume of about 42.5 liters $\left(1.5 \mathrm{ft}^{3}\right)$, gains in projectile velocity were minimal.

By varying the breech pressure the performance curve shown in Fig. I was calculated. An attempt to optimize some of the parameters (such as transition section pressure and piston mass) produced a calculated maximum projectile velocity of about $4 \mathrm{~km} / \mathrm{s}$. Comparing the optimized gas breech data to that of the powder breech indicates that the gas breech gives a lower projectile velocity by about $13 \%$.

A number of calculations were done for a smaller bore $(33-\mathrm{mm})$ to estimate the maximum projectile velocities that might be attained with our gun. The data are plotted in Fig. 2; the projectile velocity is shown as a function of maximum transition section pressure. Several parameters were varied to produce this data so some scatter is expected. (In practice the gun parameters will be controlled so maximum transition section pressures stay below 190,000 psi.) The data indicate that, with a projectile mass of $50 \mathrm{~g}$. velocities between 4 and $7 \mathrm{~km} / \mathrm{s}$ could be possible.

\section{Final Gun Configuration}

These and other calculations helped considerably in setting the final gun design. A schematic of the new TS gun with the gas breech attached is shown in Fig. 3. The figure shows a third hydraulic clamp at the breech/pump tube joint. This clamp is a redesigned pump tube/transition section joint clamp. The gun support structure was fabricated locally but the large gun pieces including the launch tubes, pump tubc, brecch, hydraulic clamps, and transition sections were fabricated by Honematic Machine Corp. 4

\section{Barrel \& Transition Section}

The pump tube ID was set a $100 \mathrm{~mm}$ and the length at $7.6 \mathrm{~m}$. Two launch tubes were made with 33- and 50-mm IDs and the length was set at $7.6 \mathrm{~m}$. These lengths represent an increase from $4.9 \mathrm{~m}$ in the Stilp gun.

We have some concem about the pump tube to launch tube diameter ratio being only 2 (rather than 2.5 or larger as normally is the case). This may lead to pump piston extrusion into the launch

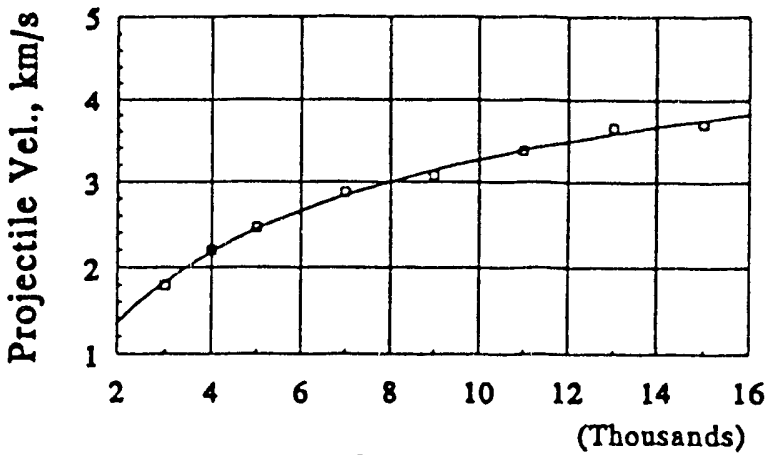

Breech Pressure, psi

Figure 1. Plot of projectile velocity versus gas breech pressure for the gas breech (volume 42.5 liters) driven gun described in this paper. The launch tube was $50-\mathrm{mm}$ diameter and the projectile mass was $200 \mathrm{~g}$.

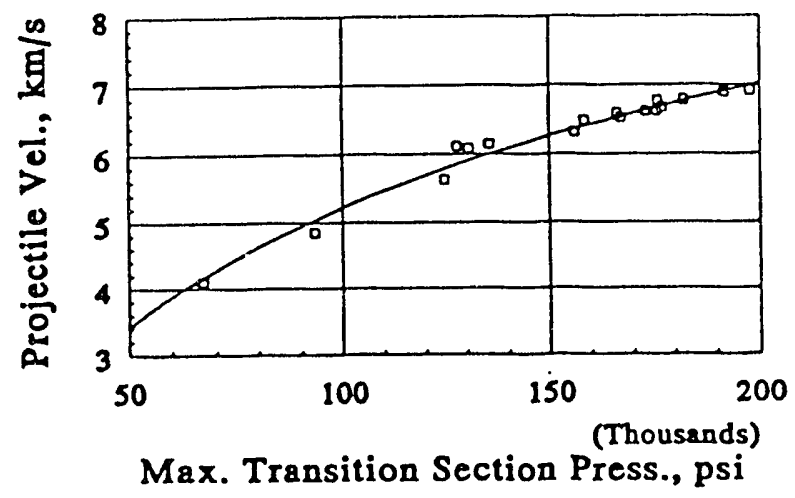

Figure 2. Plot of projectile velocity versus gas breech pressure for the gas breoch (volume 42.5 liters) gun described in this paper. The launch tube was 33- $\mathrm{mm}$ diameter and the projoctile mass was $50 \mathrm{~g}$.

tube during a shot, a problem that has been experienced by others in the past. Two transition sections were designed, one with a ten-degree and the other with a twenty-degree included angle transition. It is hoped that the larger angle unit may help alleviate this problem if it occurs.

\section{Gas Breech}

A gas breech was designed with a volume of 42.5 liters and a 15,000 psi pressure capability. The design was based on the 15,000 psi double diaphragm breech routinely used on our SS gun 
and also on a design that includes interchangeable inserts for wrap-around and double-diaphragm operation.5 The data of Fig. 1 show that breech pressures between 3000 and 8000 psi produce projectile velocities between about 1.5 and 3.0 $\mathrm{km} / \mathrm{s}$, the range where we expect to do most of our shots. Since a wrap-around breech could be operated in this pressure regime at a considerable savings, we designed the interchangeable wraparound insert. A cross-sectional view of the breech/barrel/ hydraulic clamp arrangement is shown in Fig. 4.

In the wrap-around mode the back of the pump piston acts as the breech valve so an aluminum piston back with o-ring seals was designed. The front of the piston will be polyethylene as is normally the case. Firing the gun in this mode is accomplished by injecting gas behind the piston to start it moving and uncover the breech gas channels that connect the barrel to the breech volume.

In double-diaphragm mode two diaphragms are used with half the breech pressure across each one. Firing the gun in this mode is accomplished by venting the gas between the diaphragms, causiifg the breech gas to overpressure the first diaphragm, then the second diaphragm, and then accelerate the pump piston. Pure nickel diaphragms approximately $5-\mathrm{mm}$ thick will be used.

\section{Target Chamber and Catch Tank}

A target chamber/catch tank system was not part of the Stilp design so we slightly modified our single-stage gun system to accommodate the larger launch tube. The inside diameter is $1 \mathrm{~m}$ and the joined logether length is about $4 \mathrm{~m}$. This system was fabricated 6 of $19-\mathrm{mm}$ thick pressure vessel steel and is capable of containing $150 \mathrm{psi}$ after a shot. The inside diameter of the target chamber provides ample room to install an electromagnet assembly so that magnetic gauging experiments can be done.

\section{Gun Control System}

Control of the gun will be accomplished using a MAC computer and LabVIEW control software? in the same manner that it is now being used to control our single-stage gun. The computer is the interface between the opisator and the gun so that the gun is pressurized and controlled manually using a mouse to click on the icons that represent the valves and firing control buttons.

\section{GUN COMPLETION SCHEDULE}

All the gun parts, including the support structure, the breech, barrels, transition section, hydraulic clamps, and target chamber and catch tank are installed and aligned. The hydraulic systems to operate the hydraulic clamps are operational. Gun and building interlocks, ubservation equipment, and control points are being installed and wired to the control system at the present time. We are setting up to do a 25,000 psi hydraulic pressure test of the gun system with the hydraulic clamps holding the system together and an appropriate plug at the end of the launch tube. This represents a 1.5 times over test of the breech and will also demonstrate the integrity of the other gun components. After this test, the control system and gas pressurization system must be completed. We expect to begin preliminary testing in late summer 1993 with experiments on IHE materials following in the fall.

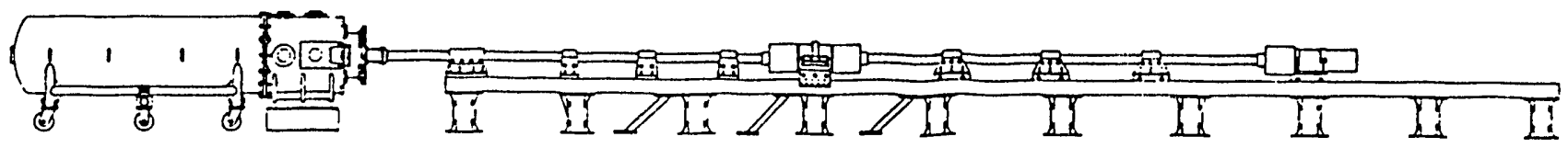

Figure 3. Schematic of the new two-stage gun at LANL, including the support structure and the target chamber and catch tank. The support structure is $18-\mathrm{m}$ long with each of the barrels 7.6-m long. The target chamber/catch tank assembly is $1-\mathrm{m}$ diameter and 4.7-m long with the walls $19-\mathrm{mm}$ thick pressure vessel steel. 


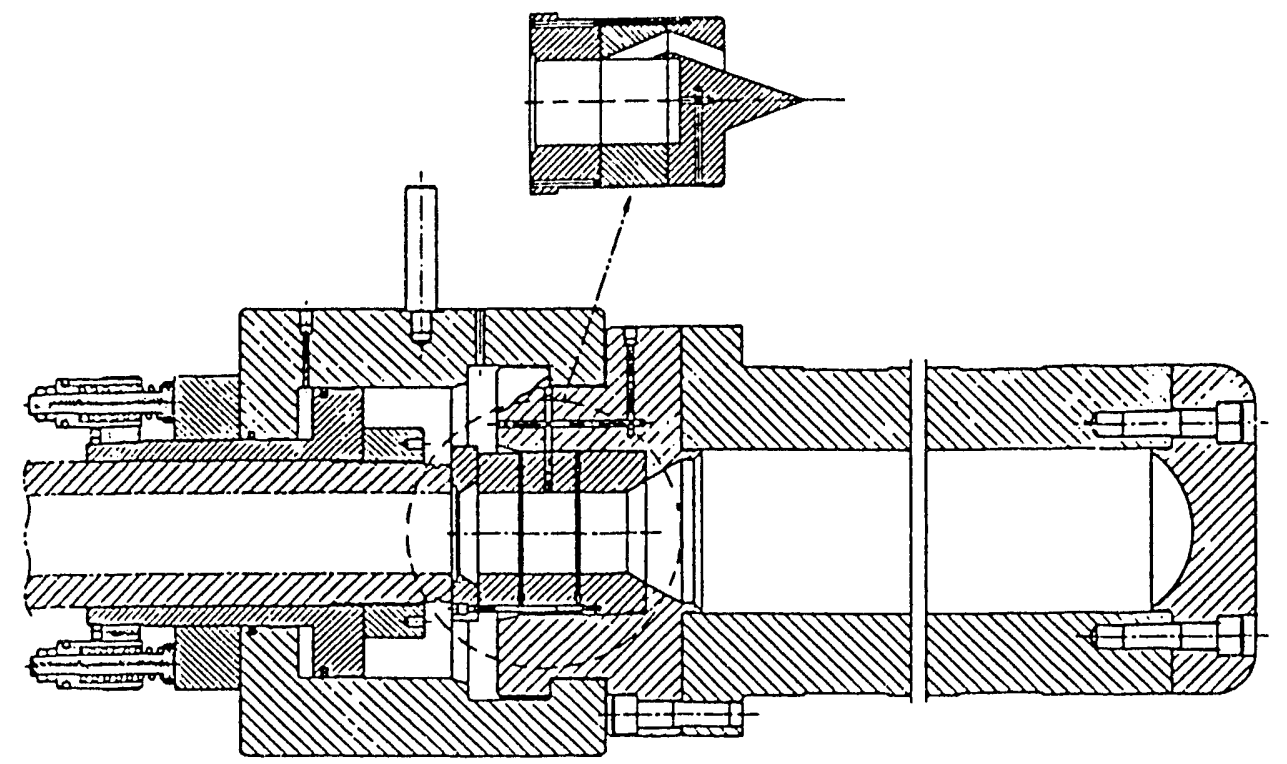

Figure 4 Cross-section of the gas breech/pump tube joint with the double-diaphragm package in place. A cross-section of the wrap-around insert is also sbown. These two inserts are interchangeable.

\section{ACKNOWLEDGMENTS}

Alois Stilp of EMI helped a great deal in German/English translations of the gun design and provided operational data on his gun. Mike Williams redrew and helped modify many of the gun parts. George Friedman and the late Allan Glazer of Honematic Machine Corporation made sure the gun fabrication went as planned. Doug Dugan of Sandia National Labs. designed the first interchangeable double-diaphragm and wraparound breech system.

\section{REFERENCES}

[1] Hypervelocity Impact Range," unpublished report. Ernst Mach Institut, Freiburg. Germany, August 1987.

[2] PTS is an abbreviation for Physikalisch-TecbniscbeStudien GmbH, Leinenweberstr. 16, D-7800 Freiburg, Germany. Peter Seidl was the contact.

[3] A. C. Charters and David K. Sangster, "Fortran Computer Program for the Interior Ballistic Analysis of Light-Gas Guns," July 1973, unpublished report, Santa Barbara, CA.

[4] Honematic Machine Corporation is located at 22 Shrewsbury Street, Boylston, MA 01505.

[5] S. A. Sbeffield and D. W. Dugan, "Description of a New 63-mm Diameter Gas Gun Facility", in Sbock Waves in Condensed Matter. Ed. Y. M. Gupta, Plenum Press, New York, 1986, p. 565.
[6] The target chamber/catch tank system was manufactured by Terminal Manufacturing Co., Berkeley, CA.

[7] LabVIEW is a computer program developed by $\mathrm{Na}$ tional Instruments, 6504 Bridge Point Parkway, Austin. TX. It was designed to allow MAC computer control of equipment. 

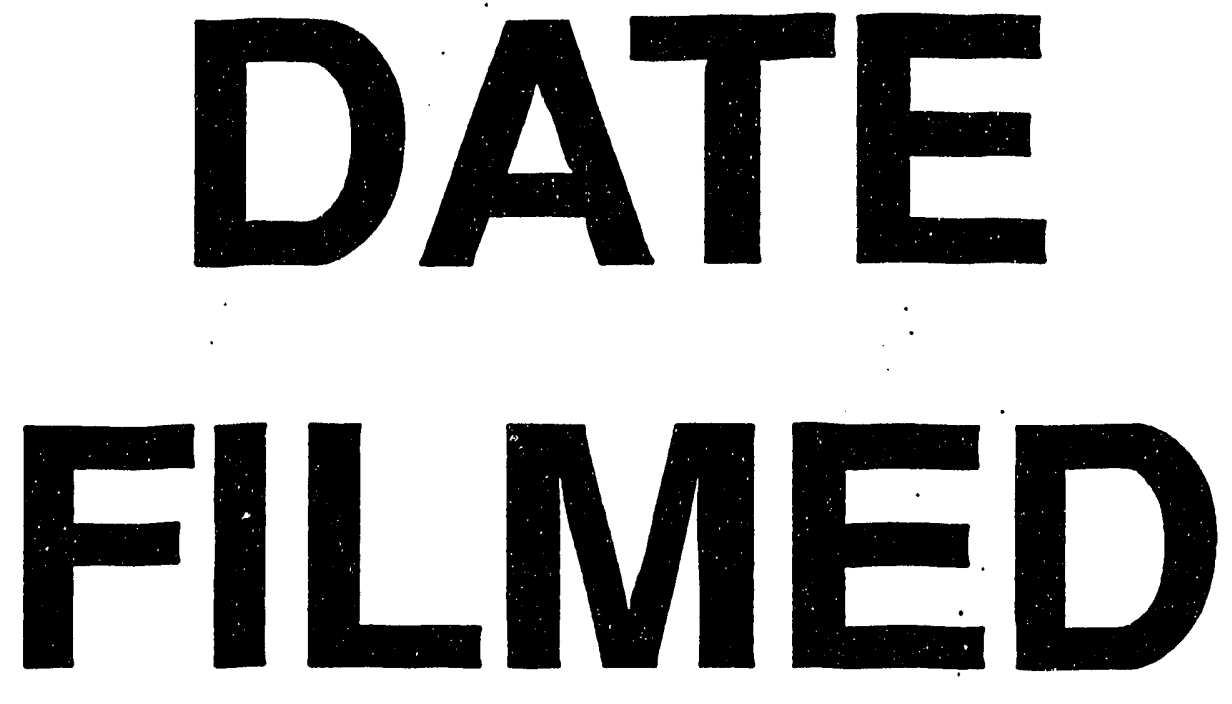

$10 / 20 / 93$
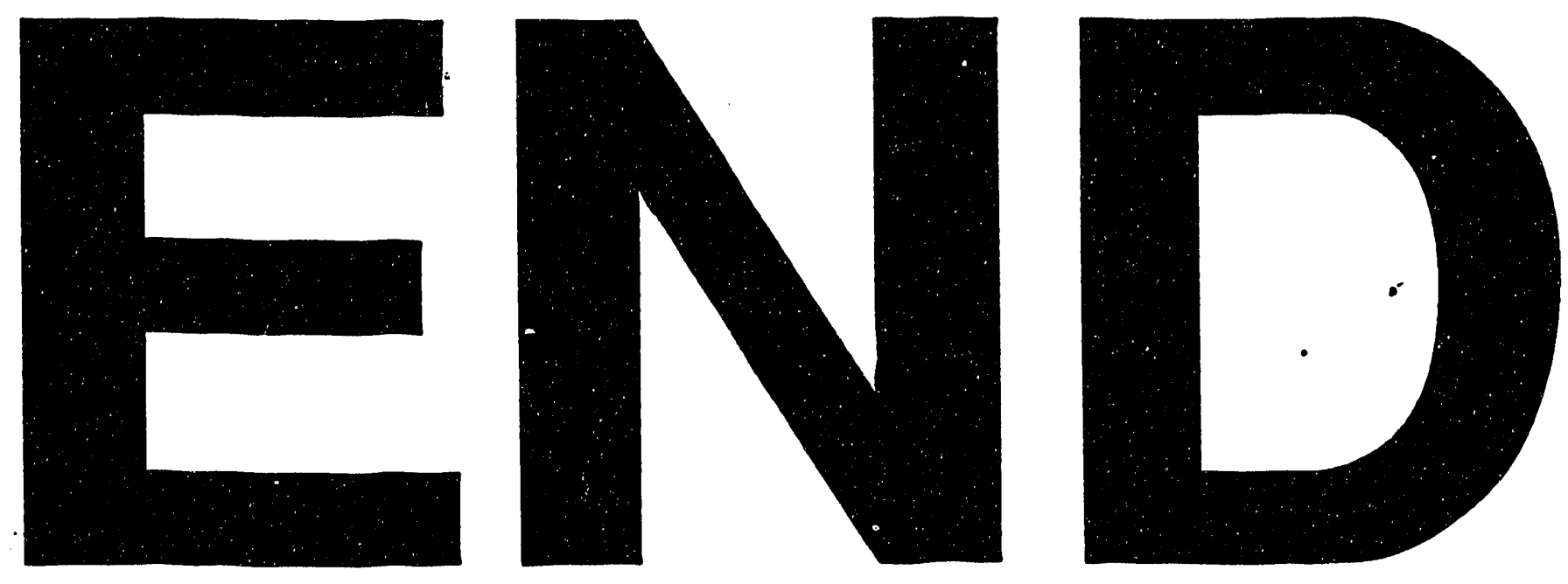
